\title{
High-Speed Characterization of ECN Spray A Using Various Diagnostic Techniques
}

\author{
Maarten Meijer \\ Eindhoven University Of Technology \\ Jonas Galle \\ Ghent University \\ L.M.T. Somers \\ Eindhoven University Of Technology \\ J.G.H Griensven \\ Technical University - Eindhoven \\ Sebastian Verhelst \\ Ghent University
}

\begin{abstract}
Diesel spray experimentation at controlled high-temperature and high-pressure conditions is intended to provide a more fundamental understanding of diesel combustion than can be achieved in engine experiments. This level of understanding is needed to develop the high-fidelity multi-scale CFD models that will be used to optimize future engine designs.

Several spray chamber facilities capable of high-temperature, high-pressure conditions typical of engine combustion have been developed, but because of the uniqueness of each facility, there are uncertainties about their operation. The Engine Combustion Network (ECN) is a worldwide group of institutions using combustion vessels, whose aim is to advance the state of spray and combustion knowledge at engine-relevant conditions. A key activity is the use of spray chamber facilities operated at specific target conditions in order to leverage research capabilities and advanced diagnostics of all ECN participants. The first target condition, called "Spray A", has been defined with detailed ambient and injector conditions.

For this paper, we describe results from the constant-volume pre-burn vessel at Eindhoven University of Technology. The executed measurements include a wide range of diagnostics to characterize "spray A" in reacting and non-reacting conditions in great detail. Observations of spray penetration, ignition, liquid length and flame lift-off location by using several high-speed imaging diagnostics are discussed and compared with other ECN participating institutes.

Comparison Spray A data from the other participating institutes, as it was presented during the $2^{\text {nd }}$ ECN workshop is gathered from the ECN website database [1]. It can be concluded that the obtained results from the standardized ECN spray diagnostics, show satisfactory similarity, despite of the challenge to reach similar boundary conditions (ambient and injector) in each of the unique facilities. The differences in results are within the measurement deviation and uncertainty or can be explained by the usage of (slightly) different injectors. Combining the results of the different measurement techniques provides an overall (time resolved) overview where the different phases of fuel injection are directly linked and summarized. The presented overview provides a direct input for (CFD) modeling validation.
\end{abstract}

CITATION: Meijer, M., Galle, J., Somers, L., Griensven, J. et al., "High-Speed Characterization of ECN Spray A Using Various Diagnostic Techniques," SAE Int. J. Engines 6(2):2013, doi:10.4271/2013-01-1616. 


\section{INTRODUCTION}

Spray A is related to a relatively low-temperature diesel engine combustion condition relevant to engines that use a moderate rate of EGR. The most relevant boundary conditions and injection properties are summarized in table 1. A more detailed description can be found at www.sandia.gov/ecn [1]. The selected injection lay-out and injection pressure are based on modern advanced commonrail injection systems. In addition the injector, common rail, fuel line and specific details such as the location of the fuel line are specified to ensure consistent hydraulic effects during injection.

A single-component diesel surrogate fuel; n-dodecane, is chosen to enable a complete specification of the chemical and physical properties of the fuel. Furthermore, n-dodecane is often used as a single component surrogate fuel; because it's $\mathrm{H} / \mathrm{C}$ ratio and boiling temperature characteristics are comparable to diesel. Detailed chemical kinetic mechanisms exist for n-dodecane allowing full treatment of the combustion chemistry [2].

Table 1. Overview "spray A" boundary conditions and hardware. *Ambient conditions are referred to the core properties in the vessel

\begin{tabular}{|l|l|}
\hline Ambient gas density* $\left[\mathrm{kg} / \mathrm{m}^{3}\right]$ & 22.8 \\
\hline Ambient oxygen conc $[\mathrm{vol} \%]$ & $0 \& 15 \%$ \\
\hline Ambient gas temperature* $[\mathrm{K}]$ & 900 \\
\hline Ambient gas velocity $[\mathrm{m} / \mathrm{s}]$ & $<1$ \\
\hline Nozzle outlet diameter $[\mu \mathrm{m}]$ & $90($ single nozzle) \\
\hline Nozzle K factor $[-]$ & 1.5 \\
\hline Discharge coefficient $[-]$ & 0.86 \\
\hline Mini-sac volume $\left[\mathrm{mm}^{3}\right]$ & 0.2 \\
\hline Injection pressure $(\mathrm{MPa})$ & 150 \\
\hline Fuel & n-dodecane \\
\hline Fuel temperature $[\mathrm{K}]$ & 363 \\
\hline Injection duration $[\mathrm{ms}]$ & 1.5 \\
\hline
\end{tabular}

\section{EXPERIMENTAL SETUP}

The used test apparatus for the presented work is the Eindhoven High Pressure Cell (EHPC). Main vessel dimensions and other main characteristics are given in table 2 and an image of the set-up is presented in figure 1. More comprehensive details regarding this particular setup can be found in []ㅡ.
Table 2. Main combustion vessel characteristics

\begin{tabular}{|l|l|}
\hline Window aperture & $100 \mathrm{~mm}$ \\
\hline Chamber volume & $1260 \mathrm{~cm}^{3}$ \\
\hline Injector mounting & Horizontally, side window \\
\hline Injector tip protrusion & $5 \mathrm{~mm}$ \\
\hline Mixing fan location & Upper corner near injector \\
\hline Fan speed & App. $1900 \mathrm{rpm}$ \\
\hline $\begin{array}{l}\text { Spark plug position } \\
(2 \mathrm{x})\end{array}$ & $\begin{array}{l}\text { Opposite Diagonal corners, top } \\
\text { \& bottom. }\end{array}$ \\
\hline Inner body temperature & $453 \mathrm{~K}$ \\
\hline Combustible gas fill & sequential \\
\hline
\end{tabular}

The EHPC is an optically accessible constant volume combustion vessel where elevated temperature and pressure conditions are created by using the so-called pre-combustion method. The desired ambient conditions at the moment of fuel injection are created by igniting a carefully selected combustible premixed gas mixture inside the combustion chamber. The constant volume high pressure combustion vessel is optically accessible through three $50 \mathrm{~mm}$ thick Sapphire windows with a diameter of $100 \mathrm{~mm}$. The inner combustion chamber walls are heated to $453 \mathrm{~K}$.

Following the spark-ignited premixed combustion, the combustion products cool down over a relatively long time due to heat transfer to the vessel walls and the vessel pressure slowly decreases. Multiple spark plugs are utilized in combination with high capacity coils to provide consistent ignition of fuel-lean mixtures. A mixing fan stirs the gases during filling and throughout the complete experiment to minimize mixture density and temperature non-uniformities. A relatively low fan speed is selected in order not to exceed the prescribed ambient gas velocity of $1 \mathrm{~m} / \mathrm{s}$. When the desired pressure and temperature are reached, the diesel fuel injector is triggered and fuel injection occurs.

An important aspect of the ECN is to perform experiments under well-defined and controlled conditions. The characterization of these conditions for the EHPC and a comprehensive review on these conditions for other institutes can be found in ref $[\underline{2}, \underline{4}]$.
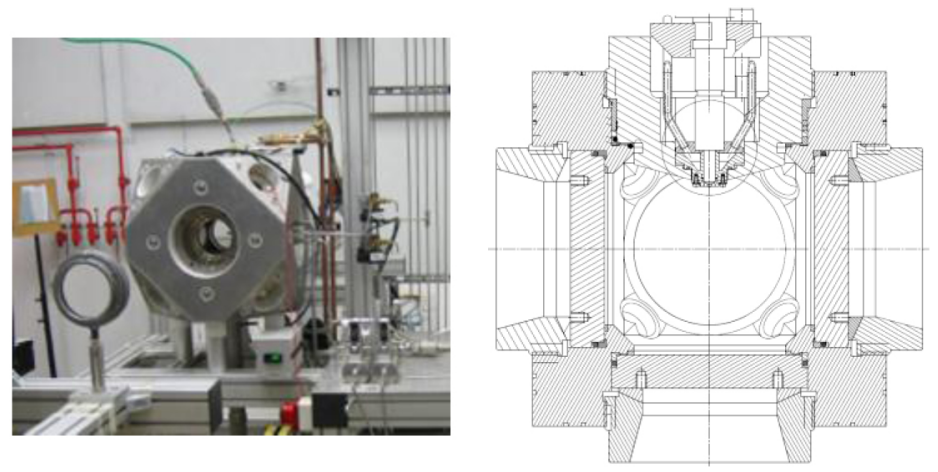

Figure 1. Used experimental set-up: the EHPC pre-burn combustion vessel. Right schematic: top view. 


\section{ECN "Spray A" Hardware}

A limited set of well characterized dedicated injectors is available for ECN "spray A" diagnostics. All injectors are manufactured according to the same specifications but small differences still exist. Therefore each individual injector is characterized in large detail [1]. For the TU/e experiments, described in this paper, "Spray A" injector with serial number 679 is used.

The different nozzles used by the different participating institutes are shown in table 3 . When comparing results from the different participating institutes, it is important to consider the effects of the differences in nozzle diameters. Corrections were made, based on earlier reported 0D models for the nozzle diameter for the flame lift-off length (FLOL) []], liquid length (LL) and spray penetration [6].

Table 3. Nozzles and their measured diameter used by the different institutes for "spray $A$ " measurements. The theoretical diameter is $90 \mu \mathrm{m}\left({ }^{*}\right.$ data obtained from ECN2 workshop)

\begin{tabular}{|l|c|c|}
\hline Institute & nozzle & Nom. Diameter* \\
\hline Sandia & $\# 677$ & 84.1 \\
\hline IFPEN & $\# 678$ & 88.6 \\
\hline CMT & $\# 675 \& \# 678$ & $89.4 \& 88.6$ \\
\hline TU/e & $\# 679$ & 83.7 \\
\hline
\end{tabular}

As high-speed measurement of fuel pressure can add much information about the hydraulics within the fuel system, and their impact on rate of injection, the location of the fuel pressure measurement is specified. This is done to promote repeatability at different facilities. All other prescribed "spray A" hardware (as indicated in the introduction section) is implemented on the EHPC set-up before starting any experiments.

Beside the standardized ECN hardware, system upgrades have been implemented to improve the measurement accuracy and repeatability. The most significant modification is the location and design of the injector window. The injector is mounted horizontally on the side of the vessel and the mounting window has a conical shape (see the schematic in Figure 1). The motivation for this is to place the injector tip outside the cold boundary layer. The horizontal mounting of the injector at the mid plane of the vessel avoids injecting in the hot gasses which are located in top of the vessel (buoyancy driven) after the pre-burn event. A ceramic injector tip cover is used to avoid an increase in temperature of the fuel due to exposure of the injector tip to the hot gasses inside the vessel after the pre-burn event.

Because of the hardware modifications, boundary conditions are re-evaluated (validated for earlier obtained results described in [4]). Injector fuel and gas (core) temperature are measured with a thermocouple instrumented "dummy" injector and fine wire thermocouples respectively. The fine wire thermocouple experiments were performed in order to define the ratio of the core and bulk temperature of the ambient gas. The last can be derived from the ideal gas law and the measured pressure during and after the precombustion. The ratio was found to be 1.08 for spray A conditions in the EHPC set-up which is similar to the value found before implementing the hardware modifications to the set-up. Knowledge of this ratio allows injecting at the correct conditions based on the pressure measurements. The used methods are described in more detail [4]. The fuel temperature distribution inside the injector is shown in figure 2. Based on the results presented in figure 2 and the fact that the required amount of fuel for one injection is located up till $4 \mathrm{~mm}$ inside the injector body volume, it can be concluded that the fuel temperature uncertainty reduced to $5 \mathrm{~K}$.

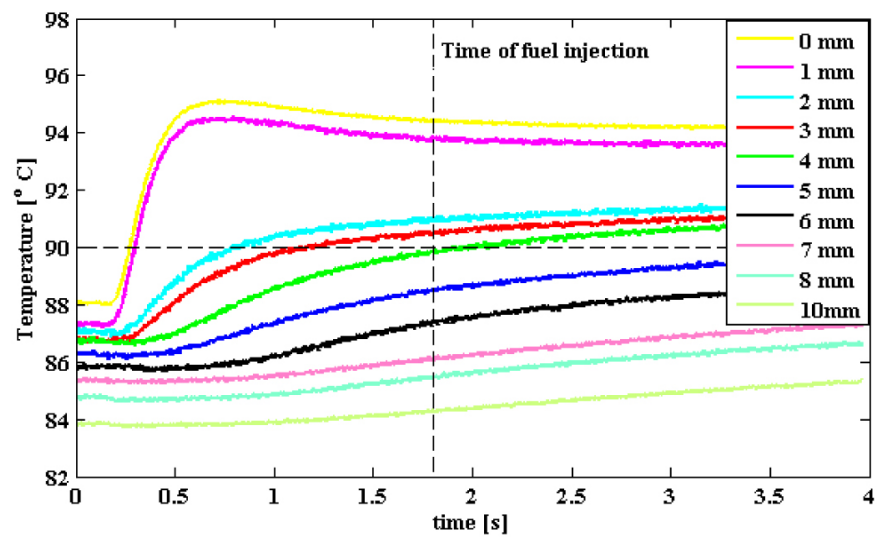

Figure 2. Injector fuel temperature distribution at different locations inside the injector nozzle.

\section{FLAME LIFT-OFF LENGTH}

An important and often studied characteristic of direct fuel spray combustion is the location where the flame front initiates and stabilizes during an injection event. The distance from the injector of reaction zone stabilization after the time of auto-ignition is traditionally called the Flame Lift-Off Length (FLOL). The FLOL has a strong effect on diesel combustion. Flame lift-off allows fuel and air to premix upstream of the lift-off length, which affects the combustion and soot formation processes downstream [ $[5]$. In this section FLOL measurement techniques and results are discussed. A high speed imaging method is implemented in order to obtain a time-resolved overview of the FLOL behavior.

The presented FLOL measurements are based on intensified high speed recordings. The detection of hightemperature chemiluminescence from excited-state $\mathrm{OH}$ $\left(\mathrm{OH}^{*}\right)$ indicates the location of the flame [5]. Normally $\mathrm{OH}^{*}$ measurements are executed with a (single shot) ICCD camera and a relatively long exposure time (app. $0.5 \mathrm{~ms}$ ). In this case the low intensity signals are intensified by a high speed intensified relay optic system (LaVision IRO) which is lens coupled to a high speed camera (Phantom V7.3). A 310 (10 $\mathrm{nm}$ FWHM) optical bandpass filter is used for the experiments in order to capture the light emitted by the $\mathrm{OH}^{*}$ molecules and to block and avoid overexposure, primarily 
caused by soot incandescence as much as possible. A schematic overview of the setup is shown in figure 3 and the used settings for the camera and intensifier are shown in table $\underline{4}$.

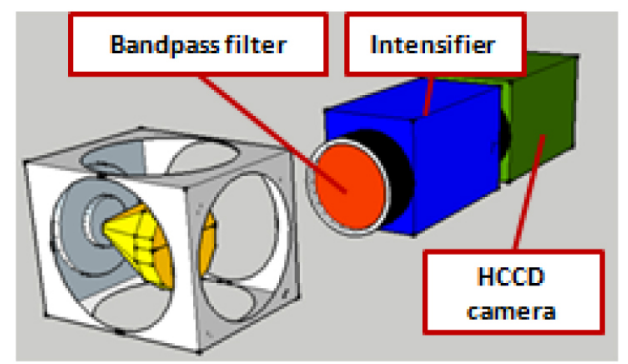

Figure 3. Schematic overview of the optical set-up used for FLOL measurements.

Table 4. Settings flame lift-off length measurements.

\begin{tabular}{|l|l|}
\hline Frame rate & $21[\mathrm{kHz}]$ \\
\hline Resolution & $0.2041[\mathrm{~mm} / \mathrm{px}]$ \\
\hline Gating time & $20[\mathrm{us}]$ \\
\hline Gain [\%] & $75[\%]$ \\
\hline Bandpass filter & $310[\mathrm{~nm}]$ \\
\hline
\end{tabular}

Post-processing of the FLOL recordings is done in 2 different ways. The first method is dedicated to make a direct comparison with the obtained measurement data from the other participating ECN institutes; Sandia, IFPEN and CMT. These institutes all used single shot ICCD cameras with a relatively long exposure time to capture the steady FLOL resulting in a "chip averaged" image [7],[]. Therefore for each TU/e experiment, a time-averaged image was generated by averaging the individual shots within the steady FLOL period of the injection.

For direct CFD modeling validation, the time resolved evolution of the location of $\mathrm{OH}^{*}$ will give a better insight in the evolution of the flame. For this method both the minimum and maximum location are of interest. In this case, the minimum distance can be regarded as the traditionally defined FLOL and the head of the flame as the maximum flame penetration.

The time averaged FLOL threshold is traditionally defined as; the position at which $50 \%$ of the maximum intensity from the "knee" value is reached. The intensity profile is obtained along axial spray axis [7]. An example of an obtained intensity profile is shown in figure 4.
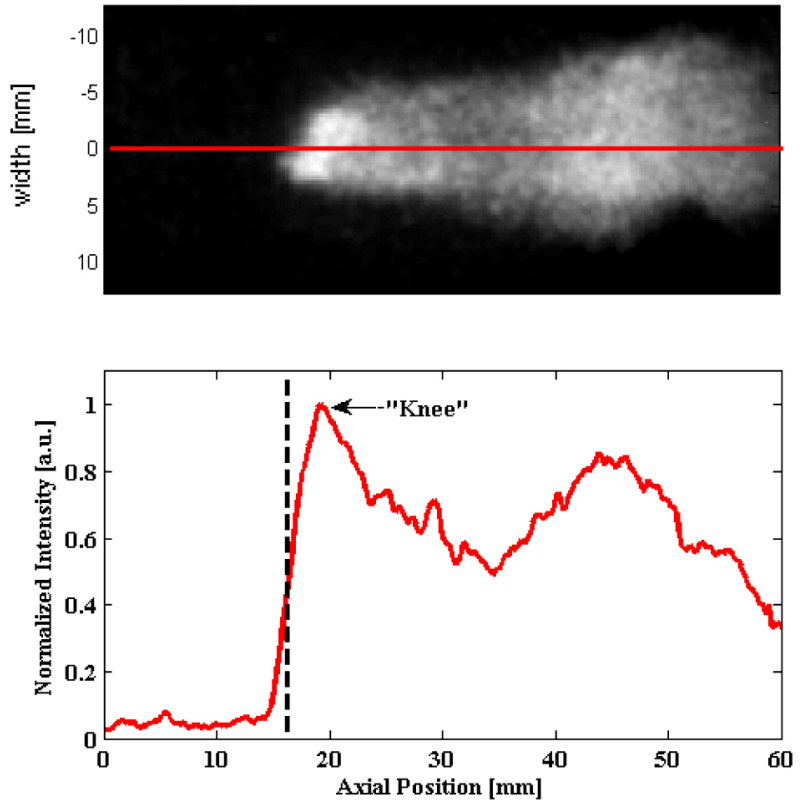

Figure 4. Time averaged FLOL post-processing method. Showing the FLOL based on the 50\% max intensity.

One conclusion drawn from the obtained images is that the used measurement approach suffers from internal reflections from the, uncoated and therefore (too) shiny, combustion vessel walls. The slight increase in intensity observed from the injector tip at $0 \mathrm{~mm}$ up-till app. $15 \mathrm{~mm}$ downstream reveals this effect on the intensity profiles. Although this is an undesired effect, it appears not to influence the obtained result since this "noise" is far below the used threshold value.

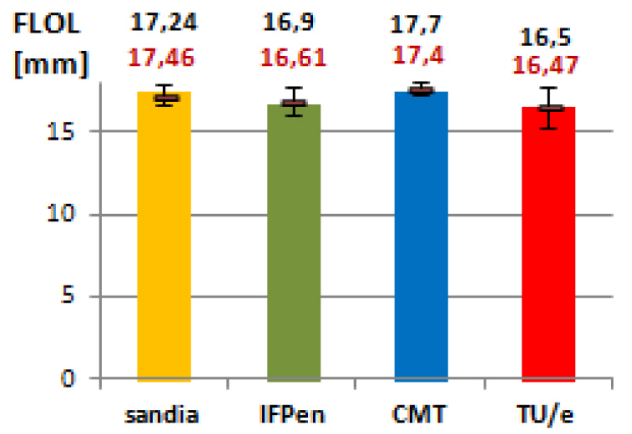

Figure 5. Comparison of the flame lift-off length (FLOL) between different institutes. The original values are shown in black at the top; the corrected values for the nozzle diameter [5] are shown in red below (data from the ECN2 workshop). 
The obtained results for the time averaged FLOL measurements are summarized in Figure 5. The results from the other ECN participants who executed FLOL measurements are also shown here. This comparison data has been taken from the Sandia website and results were discussed during the $2^{\text {nd }}$ ECN workshop [1]. Pickett et al. [5] found that the FLOL depends on the nozzle-hole diameter to the power 0.34 . The nominal injector diameters from table 3 are therefore used to correct the obtained results to make a fair comparison. This correction has been added to the results of figure 5 (indicated with the red values).

Post processing of the time resolved $\mathrm{OH}^{*}$ images is done by using the same normalized threshold value definition as it was found for the time averaged FLOL results but now a contour is drawn around the raw spray image for each individual frame. In this way, both the minimum and maximum FLOL's can be defined. A post-processed single shot $\mathrm{OH}^{*}$ image under "spray A" conditions is shown in figure 6 and a time resolved overview of the minimum and maximum FLOL is shown in Figure 7. From figure 7 it can be observed how the up-stream flame stabilizes till the end of injection while the down-stream flame at the head of the spray penetrates in axial direction. At the end of injection the upstream flame (FLOL) rapidly moves downstream and merges with the head of the spray till the flame quenches (black line). In some cases, but not always, it is noticed that at the end of injection the minimum FLOL not only moves downstream but splits and also moves back upstream to the injector tip. This phenomenon is presented in figure 7 by the green dots. The reason why this upstream movement doesn't occur for every injection event is not well understood at this moment and can't be explained based on the other available measured variables. Future work to investigate this more in detail is therefore recommended.

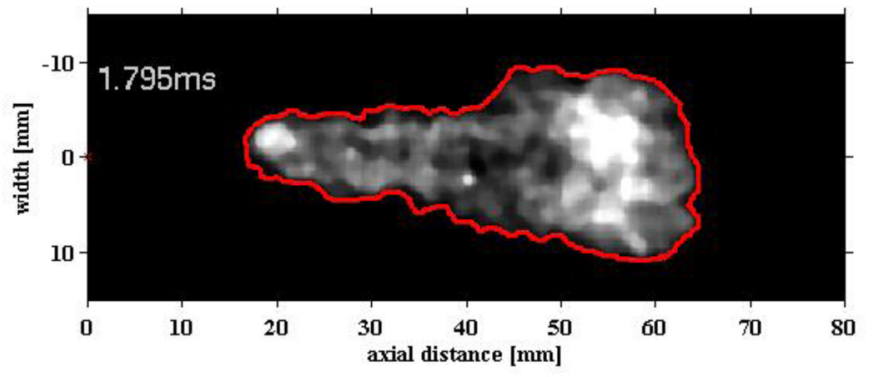

Figure 6. Post-processed single shot intensified $\mathrm{OH}^{*}$ image

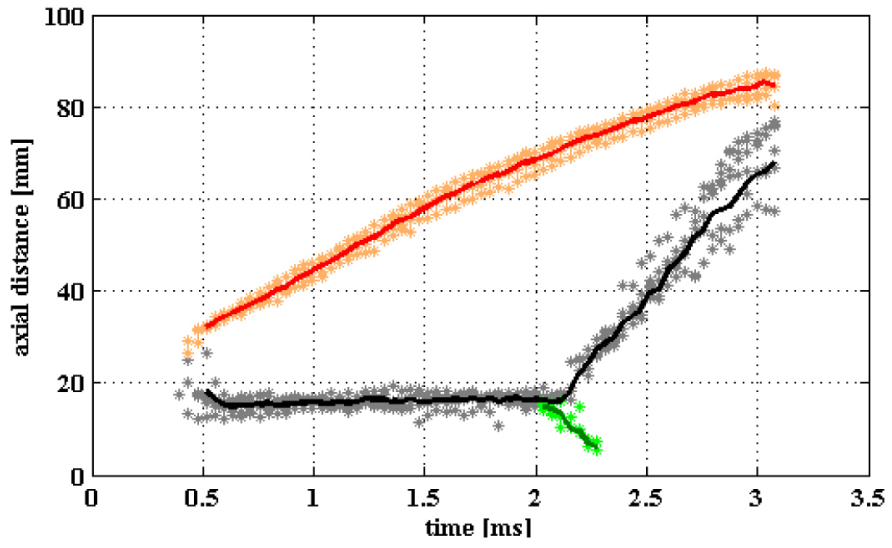

Figure 7. Time resolved FLOL and maximum flame penetration.

\section{IGNITION DELAY}

An important parameter of spray combustion is the moment and location where the combustion process initiates. In this section, simultaneous measurements for the initial preignition cool flame and the start of high temperature combustion; ignition, are discussed. The ignition delay can be determined based on natural luminosity or the change in pressure of the ambient gas inside the vessel. Both methods are implemented and evaluated.

The goal of the light based ignition delay measurements is to capture the first emission of light emitted at the preignition cool flame start. The natural luminosity derived ignition delay is largely based on the same intensified high speed recording set-up as it was presented in the FLOL section. Important difference is that the $310 \mathrm{~nm}$ optical filter is not used here. In this way the strong $\mathrm{HCHO}^{*}$ and $\mathrm{HCO}^{*}$ emission in pre-ignition cool flames can be captured and used to identify the region where cool flame chemistry occurs prior to high temperature combustion $[\underline{5}, \underline{9}, \underline{10}]$. Also the camera signal intensity will increase significantly since the earlier used bandpass filter has a low transmittance level (15 $\%)$. Note that the earlier motivation to use this filter for suppression of soot incandescence is less relevant for the early cool flame ignition detection since soot is believed not to be present here. Also for the ignition delay measurements, the region of interest has been reduced to minimize the utilized area on the high speed camera CMOS chip. This enables the maximum possible frame rate. The used measurement settings are summarized in table 5. High intensity soot incandescence appears directly after start of the high temperature combustion which will fully saturate the captured images if no measures are taken. In order not to damage the intensifier by overexposure from the high intense luminosity from soot, the intensifier is deactivated directly after ignition. 
Table 5. Settings for light intensity based ignition delay (ID) measurements.

\begin{tabular}{|l|c|}
\hline Frame rate [kHz] & 41 \\
\hline Resolution [mm/px] & 0.2041 \\
\hline Gating time [us] & 20 \\
\hline Gain [\%] & 85 \\
\hline
\end{tabular}

As stated, in the combustion process, one can distinguish a cool and a hot flame stage ignition. The cool flame can only be measured by capturing the emitted light by natural luminosity because it is not notable in the recorded pressure (no detectable heat release occurs). Result images for the by natural luminosity measurements are shown in figure 8 . The cool flame is defined as the moment at which the first light is detected.

The start of ignition is detected by the observation that the initial cool flames all merge together, the intensity of the luminosity goes up significantly and the flame front starts to expand. After applying, a software based, median filter, the location of the ID for both cool and hot flame is defined as the mass center of the bright spot of light. The hot flame ID is used as the ignition delay of the fuel spray for further comparisons with other institutes. It is recognized that this definition is, because of the used technique, somewhat arbitrary. For future work it is recommended to make a distinction between the pre-ignition cool flame and the hot flame ignition based on the detection of radical species such as $\mathrm{HCHO}^{*}$ and $\mathrm{HCO}^{*}$ (cool flame) and $\mathrm{OH}^{*}$ (hot flame ignition).

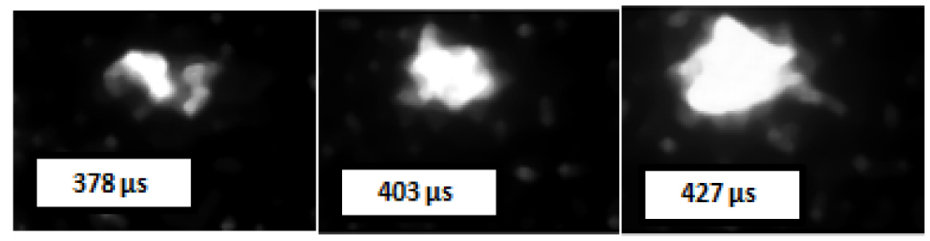

Figure 8. Succeeding time-resolved images of the initial stage of combustion ignition. Indicating cool-and hot flame ignition. $t=378$ us (cold flame ID), $t=403$ us, $t=427$ us $\left(\right.$ hot flame ID) $=\boldsymbol{t}_{\text {ign }}$.

For the pressure based ignition delay measurements a dedicated pressure sensor is installed inside the preburn combustion vessel. Normally the pressure history in the vessel is recorded with a single piëzo-electric pressure sensor and therefore the settings of the pressure sensor amplifier are selected such that the whole pressure range during one measurement event (dictated by the pre-burn event) is covered. The used measurement approach, where the dedicated sensor is optimized for ignition detection, is largely based on the method described in [1]. The settings of the amplifier are selected such that the signal-to-noise ratio around the pressure event of interest is as low as possible. With higher sensitivity to pressure, the charge amplifier would saturate and enter overload mode during the filling and pre-burn stages prior to the spray event. Therefore, the charge amplifier was kept in reset mode to continuously drain charge from the transducer until just prior to the spray event. An overview of the used hardware and settings can be found in table 6.

Table 6. used hardware and settings for the pressure based ignition delay set-up

\begin{tabular}{|l|l|}
\hline Pressure sensor & Kistler 7061: 20MPa 790pC/MPa \\
\hline Amplifier & Kistler 5011B \\
\hline Sample frequency & $30 \mathrm{kHz}$ \\
\hline
\end{tabular}

The followed post-processing method for the pressurebased ID is based on applying a correction for the pre-burn pressure decline and speed of sound pressure delay. Again the followed approach and the filtering method are described in [1]. The correction for speed of sound is based on the time ( $t$ ) it will take for a pressure wave traveling at a speed of $\mathrm{c}$ through a distance D:

$$
t=\frac{D}{c}
$$

In contrast to the proposed triangulation theory in [ 6$]$ the location (D) of the ignition in this work is directly derived from the high speed images. The speed of sound is calculated with:

$$
c=\sqrt{\frac{\gamma R T}{M}}
$$

where $\gamma$ is the ratio of specific heats, $\mathrm{R}$ the universal gas constant, $\mathrm{T}$ the temperature and $\mathrm{M}$ the molecular weight of the ambient gas. Values for this particular set-up can be found in [3]. An example of the raw and processed data is shown in figure 9. It is noted that the raw unfiltered pressure data shows a very low noise level before ignition. Since both signals (raw vs. filtered) lead to the same result, one can argue that the whole filtering method is not strictly necessary to define the ignition delay according to ECN standards. For both the cool flame and the ignition delay, the time after start of actual injection (defined as start of activation plus hydraulic delay) and the axial position are summarized in table 7. Results are typically based on 10 individual measurements. 


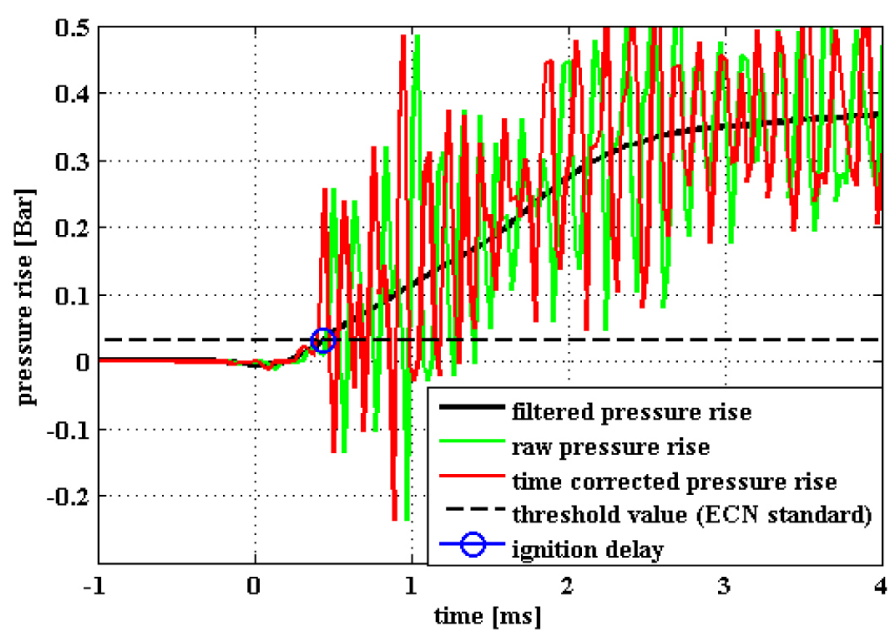

Figure 9. Pressure increase after ignition. The raw pressure signal is already corrected for preburn cool down pressure decay.

Table 7. Results for the light- and pressure based ID measurements.

\begin{tabular}{|c|c|c|}
\hline & Time $[\mu s]$ & Axial distance [mm] \\
\hline \multicolumn{3}{|c|}{ Cool flame ID } \\
\hline Average & 394 & 16.0 \\
\hline Std & 34 & 1.7 \\
\hline \multicolumn{3}{|c|}{ Hot flame ID } \\
\hline Average & 443 & 17.6 \\
\hline Std & 34 & 1.24 \\
\hline \multicolumn{3}{|c|}{ ID pressure based } \\
\hline Average & 408 & - \\
\hline Std & 38.5 & - \\
\hline
\end{tabular}

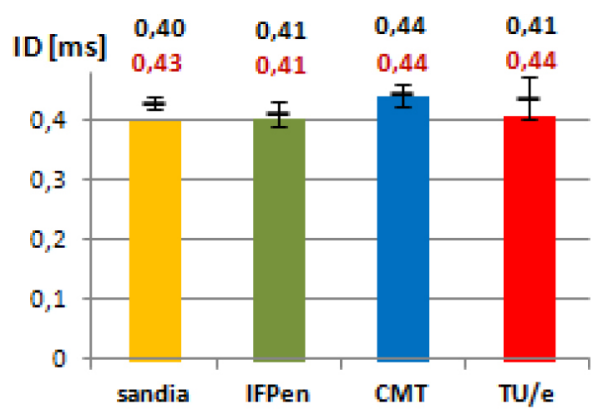

Figure 10. Comparison of the ignition delay (ID) based on the chemiluminescence between different institutes.

The original values are shown in black at the top, the corrected values for the nozzle diameter are shown in red below

An ignition delay of $443 \mu$ s is obtained, which is in line with the "spray A" results found by other institutes. A comparison of the ID is presented in figure 10. In order to have a more direct comparison a correction based on the linear dependence on the nozzle diameter is presented as well. This correlation was found by Payri et al [11].

\section{SPRAY PENETRATION}

A focused shadowgraph setup is used to measure the gas phase penetration of both inert $\left(0 \% \mathrm{O}_{2}\right)$ and reacting sprays $\left(15 \% \mathrm{O}_{2}\right)$. A blue high power LED $(460 \pm 10 \mathrm{~nm})$ acted as a light-source. The parallel light beam was formed and again focused by two $100 \mathrm{~mm}$ biconvex lenses. A small pass filter with $600 \mathrm{~nm}$ cut-off frequency was used for the reacting spray to avoid overexposed light from the soot production. Detailed settings for the HCCD Phantom V7.3 camera are summarized in table 8. The same set-up with an added spatial filter (Schlieren stop) has also been used but it was concluded that the obtained results were similar but with more noise due to the background disturbances with the Schlieren set-up.

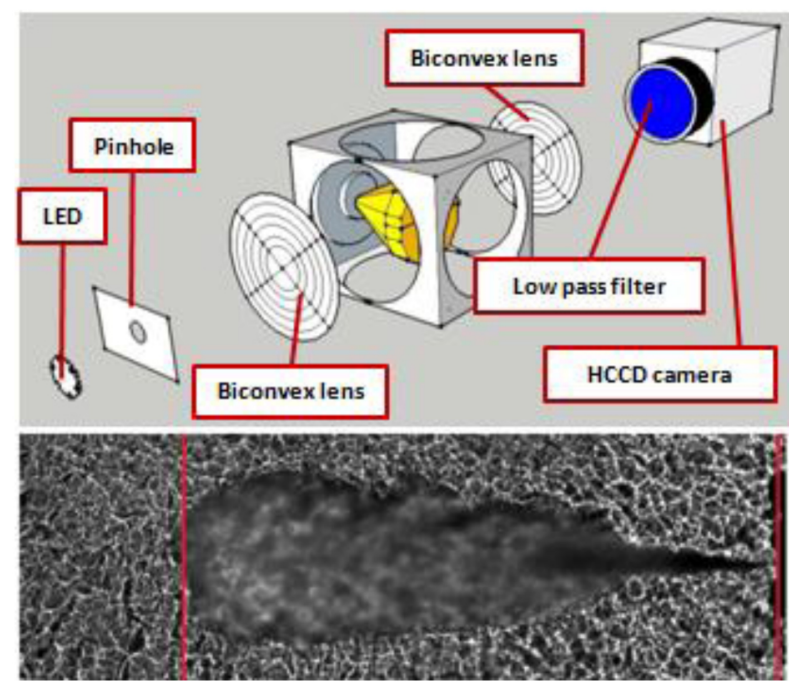

Figure 11. Used focused shadowgraphy set-up and a resulting Shadowgraph image.

Table 8. Camera settings for focused shadowgraph imaging

\begin{tabular}{|l|c|c|}
\cline { 2 - 3 } \multicolumn{1}{c|}{} & Inert & Reacting \\
\hline Frame rate $[\mathrm{kHz}]$ & 11 & 11 \\
\hline Resolution $[\mathrm{mm} / \mathrm{px}]$ & 0.1143 & 0.1143 \\
\hline shutter time $[\mathrm{us}]$ & 80 & 80 \\
\hline Small pass filter $[\mathrm{nm}]$ & none & 600 \\
\hline Focus lens & $50 \mathrm{~mm} / 1.2$ & $50 \mathrm{~mm} / 1.2$ \\
\hline
\end{tabular}

Definition of the penetration length and post-processing of the raw high speed images is done by using the standardized post processing code as it is published on the Sandia website $[\underline{1}, \underline{7}]$. The noise sensitivity for the penetration results was found reasonable since, based on earlier experiences, it is not easy to define the spray boundary from the background under these elevated ambient conditions. The fact that a relatively low measurement 
frequency was used for this work makes the disturbances by the frame to frame movements of the ambient background worse. Therefore, extra background noise correction was necessary. Applying the grain merge operation between 2 succeeding images leads to a robust post-processing algorithm:

$$
I_{\text {corr }}=\left(I_{\text {raw }}(i)-I_{\text {raw }}(i-1)+o f f \text { set }\right) * \text { fullscale }
$$

With fullscale, equal to 4096 for a 12 bit image. The offset was tuned and gave best results for a value of 0.4. Further image smoothing has been performed as developed by Xu et al. [13]. The results for the spray penetration of the inert and reacting spray are shown in figure 12 . The vertical green line represents the (hot flame) start of ignition for the reacting spray as it was discussed in the ignition delay section. The start of combustion can be clearly observed by the nod in the curve as it was also shown in [12].

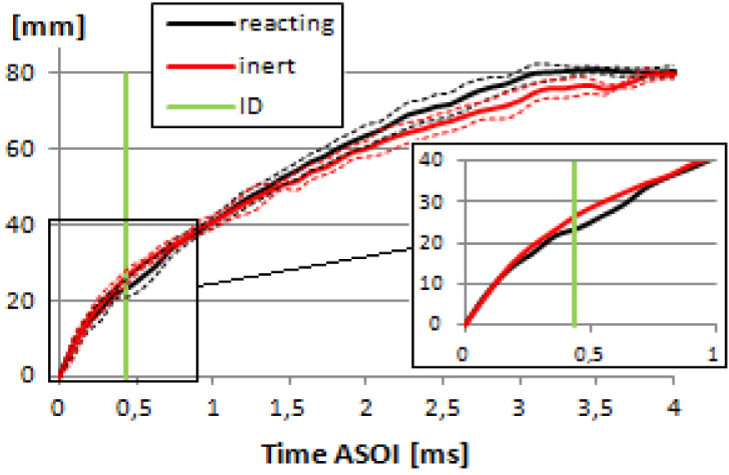

Figure 12. Spray penetration results for inert (red) and reacting (black) spray $A$. The vertical green line represents start of combustion.

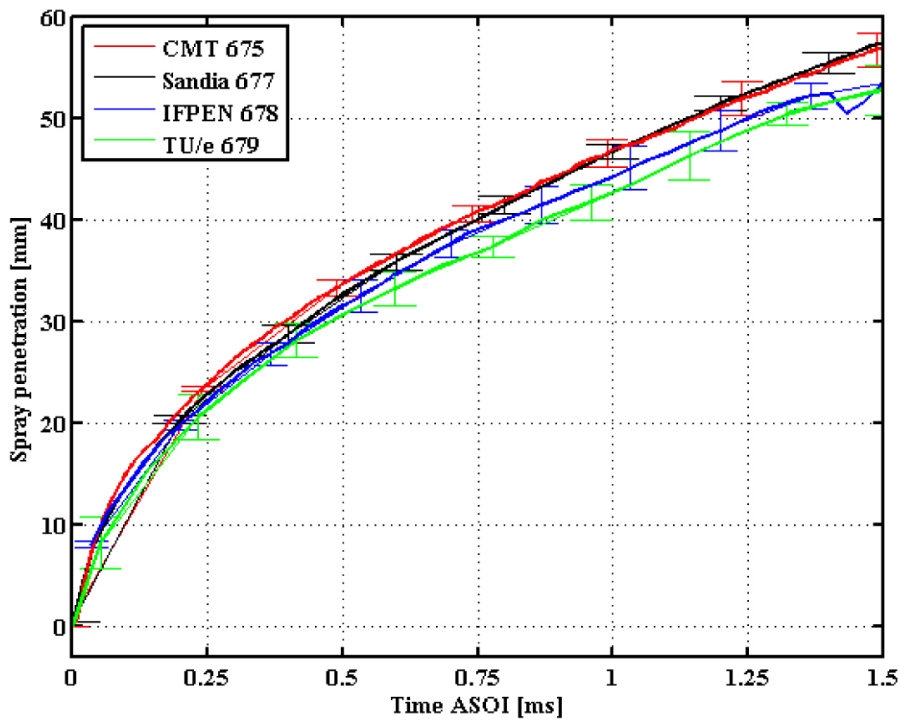

Figure 13. Comparison of the different spray penetration results from TU/e, IFPen and Sandia. Including measurement deviation.
Results are shown in figure 13 including the measurement deviations. It can be concluded that the results for Vaporphase penetration data show variations (up to $8 \%$ ) that fall within the expectations due to injector differences and measurement deviations. The spray penetration is found to scale linearly with the nozzle -hole diameter as proposed by several 0D models $[14,15]$.

\section{LIQUID PHASE}

The Liquid Length (LL) is traditionally defined as the maximum distance from the injector tip to liquid-phase fuel penetration for an evaporating fuel spray [16]. The liquid length is a fundamental parameter for spray model validation but is not easy to measure accurately. Recent studies have shown that different experimental techniques, as well as the calibration and post-processing, could lead to large variations in the measured liquid length results [16]. Being aware of the problems related to the measurement of liquid-phase penetration in evaporative sprays, the participants of the ECN agreed to use Diffused Back-Illumination imaging (DBI) to standardize results.

One reason for selecting DBI is that the incident illumination without the spray provides an intensity reference that can be used to determine the global extinction when light is attenuated by the spray. For DBI, rays are collected from multiple angles along various paths. Although beam-steering still occurs for any single ray, the integration of multiple rays onto a single pixel has the effect of smoothing the effects of beam steering on the two-dimensional results.

The light used to illuminate the spray comes from a short $50 \mathrm{~ns}$ pulsed high intensity LED light source $(460 \pm 10 \mathrm{~nm})$ in combination with a diffuser and a Fresnel lens. The diffuser is a $50^{\circ}$ square pattern and the field lens a Fresnel lens with a focal length of $152 \mathrm{~mm}$. Rather than collimation of the incoming light, a diffused bundle of rays is directed towards the spray. Images are captured by using a high speed camera (Phantom V7.3) with a frame rate of $120 \mathrm{kHz}$. A 50 $\mathrm{mm}$ camera lens is used in combination with an $8 \mathrm{~mm}$ extension ring for proper zooming. Figure 14 shows the optical setup used for diffused back-illumination imaging.

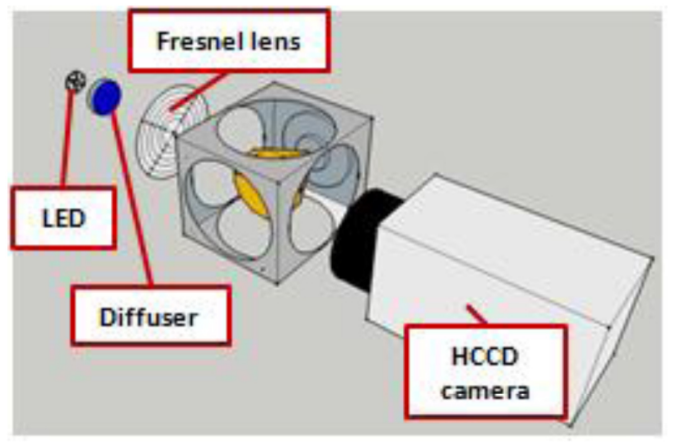

Figure 14. Schematic overview of the DBI set-up.

Two different ways of post processing are selected to define the LL. A similar approach as with the FLOL 
processing is followed; the raw data is processed such that the average and time-resolved LL can be analysed.

The time resolved LL is based on a background corrected instantaneous image. A threshold based contour around the threshold defined liquid area is drawn. The pixel at the maximum distance from the injector is defined as the time dependent liquid length. From the obtained time-resolved LL penetration (see figure 15), it can be concluded that a steady LL phase clearly exist. This particular interval of the injection event is used later on to define the steady (time averaged) liquid length.
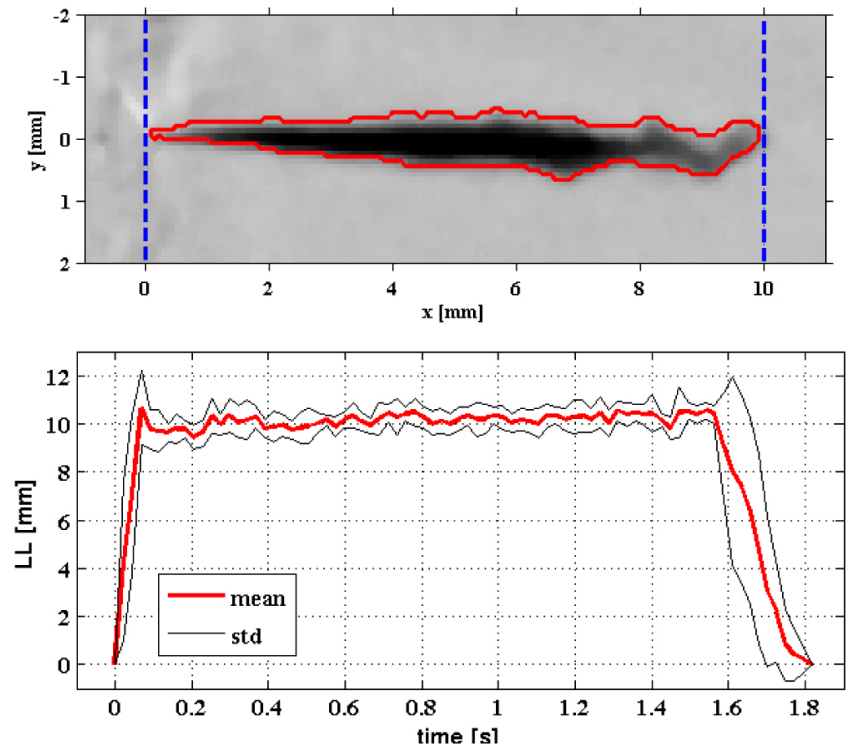

Figure 15. Time resolved (upper) and steady LL (lower) images. $L L$ defined based on the intensity along the centerline. $L L=10.33 \mathrm{~mm}$

The time averaged DBI method is based on the measurement of the light extinction through the liquid core. The reference level is the background of the image when there is no liquid injection. A mean image of the background, $<\mathrm{I}_{\mathrm{BG}}>$ is created by averaging 10 individual frames taken right before SOI. Next each image during the injection can be divided by the background image, in order to obtain the normalized intensity of the image. The logarithm of the normalized intensity gives the extinction factor $\tau$ in the whole visualization field [16]:

$$
\tau(x, y)=-\log \left(\frac{I(x, y)}{\left\langle I_{B G}\right\rangle(x, y)}\right)
$$

For the steady LL the evolution of $\tau$ along the spray axis is considered to measure the liquid length. To measure the steady-state liquid length, $\tau$ is computed on a time-averaged image, during the steady-state period of the injection; see figure 15. 10 Individual measurements are used to obtain an ensemble average together with shot-to-shot standard deviation. As explained above, this technique suffers from beam steering near the liquid spray tip, due to the refractive index gradient created by the vaporized fuel. Therefore the exact liquid length is not measured precisely. The decay of the extinction factor along the spray axis is therefore linear fitted. The location where this linear fit intercepts zero, is defined as the liquid length. The followed method and the obtained LL for "spray A" conditions are shown in figure 16.
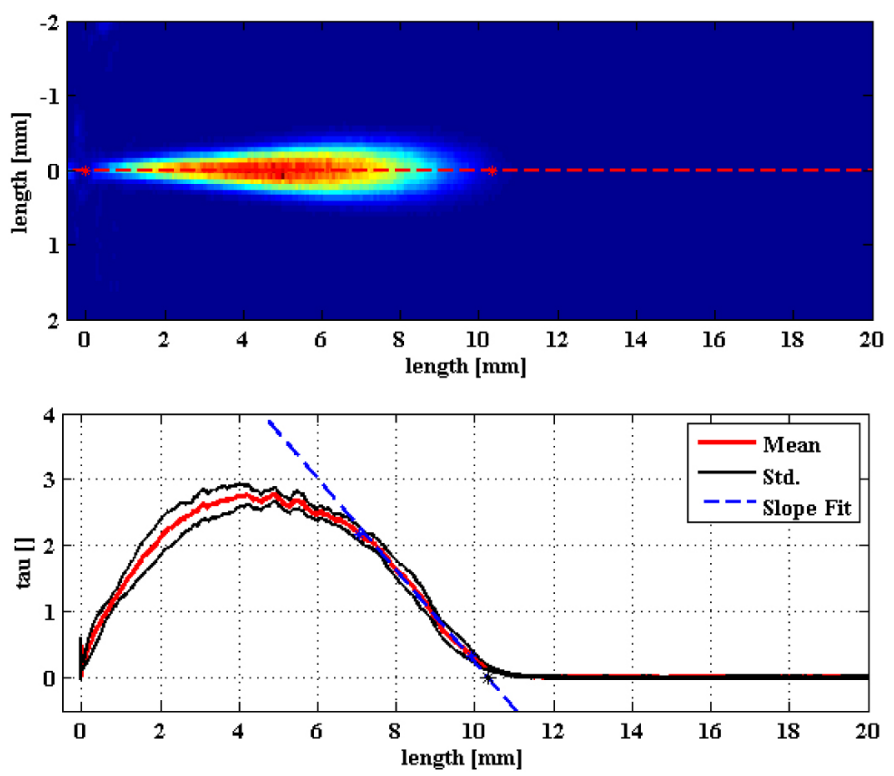

Figure 16. Average image (top) and used post-processing method to define the steady LL (bottom).

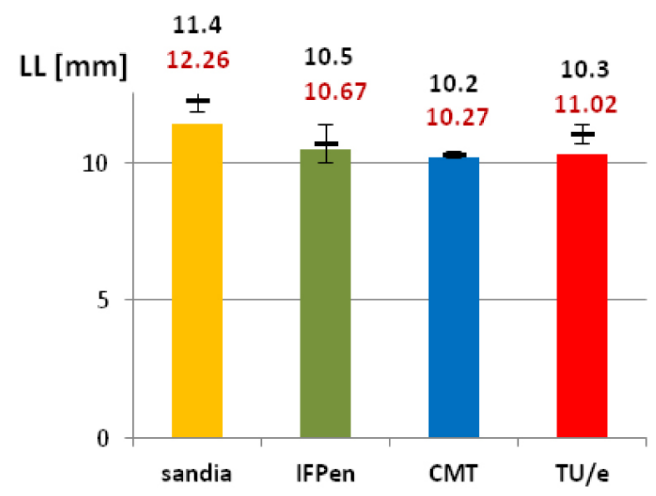

Figure 17. Comparison of the liquid length (LL) for nonreacting "spray $A$ " conditions. Showing the results from different institutes. The original values are shown in black at the top, the corrected values for the nozzle diameter [11] are shown in red below

Beside the measurements executed at the TU/e, steady LL results are provided by the following ECN participants: Sandia, IFPEN and CMT. The data is officially published and can be taken from the ECN database [1]. The obtained results are presented in figure 17. Again differences between the 
used injectors are corrected for a fair comparison (red numbers).

For these LL corrections the $0 \mathrm{D}$ liquid phase model from Siebers is used [6]. It can be concluded that the obtained results for LL are encouraging since only minor differences are found among each participant and the applied nozzle-hole correction makes this even smaller. The deviations are within the measured standard deviations.

\section{SUMMARY AND CONCLUSIONS}

Spray A has been intensively studied in the EHPC from TU/e by the use of a various range of different optical high speed diagnostics. Hardware and processing methods as proposed by the Engine Combustion Network (ECN) were applied (unless otherwise stated) to have a direct and fair comparison with measurements from other participating institutes. The evaluated parameters were liquid length, spray penetration, flame lift-off and ignition delay.

Based on the executed measurements the following conclusions can be derived from this work:

- The flame lift-off, ignition delay and liquid length and spray penetration show similar results compared to the other institutes and are within the standard deviation boundaries

- The nozzle holes for - theoretically identical - injectors differ among each other. Correction on the measurement results by the use of $0 \mathrm{D}$ models let the results converge even more when comparing to the different institutes

- Although there are known differences in liquid penetration and spray shape because of nozzle or facility differences, the combustion (ignition delay and lift-off length) measurements show consistency between institutions, suggesting a certain insensitivity of the spray details to the ultimate combustion, at least at "Spray A" conditions.

- Difficulties for the processing of shadowgraph images concerning background movement can be significantly improved by using acquisition rates higher than $20 \mathrm{kHz}$.

- It can be concluded that the results for Vapor-phase penetration data show variations (up to $8 \%$ ) that fall within the expectations due to injector differences and measurement deviations.

- Start of combustion is noted in the spray penetration data. However, a clear definition for ignition delay based on the spray penetration data is not yet proposed.

\section{REFERENCES}

1. Engine Combustion Network data archive for diesel spray combustion. http://www.sandia.gov/ECN/

2. Meijer M. et al., Engine Combustion Network (ECN): Characterization and Comparison of Boundary Conditions for Different Combustion Vessels. Atomization and Spray 60832012

3. Baert, R., Frijters, P., Somers, B., Luijten, C. et al., "Design and Operation of a High Pressure, High Temperature Cell for HD Diesel Spray Diagnostics: Guidelines and Results," SAE Technical Paper 2009-01-0649, 2009, doi: 10.4271/2009-01-0649.
4. Meijer M., Christians R.J., Griensven J.G.H. v., Somers L.M.T., de Goey L.P.H.. Engine Combustion Network: implementation and analysis of combustion vessel spray A conditions, Illass-Americas NA 23rd conference, paper 151. 2011

5. Pickett, L., Siebers, D., and Idicheria, C., "Relationship Between Ignition Processes and the Lift-Off Length of Diesel Fuel Jets," SAE Technical Paper 2005-01-3843, 2005, doi: 10.4271/2005-01-3843.

6. Siebers, D., "Liquid-Phase Fuel Penetration in Diesel Sprays," SAE Technical Paper 980809, 1998, doi: 10.4271/980809.

7. Pickett, L., Genzale, C., Bruneaux, G., Malbec, L. et al., "Comparison of Diesel Spray Combustion in Different High-Temperature, High-Pressure Facilities," SAE Int. J. Engines 3(2):156-181, 2010, doi 10.4271/2010-01-2106.

8. Meijer M., Malbec L-M., Bruneaux G., Somers L.M.T.. Engine Combustion Network: "Spray A" basic measurements and advanced diagnostics. Iclass 2012 paper 1260.

9. Higgins, B., Siebers, D., and Aradi, A., "Diesel-Spray Ignition and Premixed-Burn Behavior," SAE Technical Paper 2000-01-0940, 2000, doi: $10.4271 / 2000-01-0940$.

10. Lillo, P., Pickett, L., Persson, H., Andersson, O. et al., "Diesel Spray Ignition Detection and Spatial/Temporal Correction," SAE Int. J. Engines 5(3):1330-1346, 2012, doi: 10.4271/2012-01-1239.

11. Payri R., Salvador F.J., Gimeno J., de la Morena J., "Effects of nozzle geometry on direct injection diesel engine combustion process", Applied Thermal Engineering 29, 10(2009)2051-2060.

12. Naber, J. and Siebers, D., "Effects of Gas Density and Vaporization on Penetration and Dispersion of Diesel Sprays," SAE Technical Paper 960034, 1996, doi: $10.4271 / 960034$.

13. $\mathrm{Xu} \mathrm{L.,} \mathrm{Lu} \mathrm{C.,} \mathrm{Yi} \mathrm{Xu,} \mathrm{Jia} \mathrm{J.,} \mathrm{"Image} \mathrm{smoothing} \mathrm{via} \mathrm{L0} \mathrm{gradient}$ minimization", ACM Transactions on Graphics, 2011

14. Desantes J.M., Pastor J.V., Garcia-Oliver J.M., Pastor, "A 1D model for the description of mixing-controlled reacting diesel sprays", Combustion and Flame 156 (2009);234-249

15. Naber, J. and Siebers, D., "Effects of Gas Density and Vaporization on Penetration and Dispersion of Diesel Sprays," SAE Technical Paper 960034, 1996, doi: $10.4271 / 960034$

16. Manin J., Bardi M. and Pickett L.M.. Evaluation of the liquid length via diffused back-illumination imaging in vaporizing diesel sprays. The eighth international conference for modeling and diagnostics for advanced engine systems (COMODIA 2012), 2012

\section{CONTACT INFORMATION}

Maarten Meijer

$\underline{\text { m.meijer@tue.nl }}$

Bart Somers

L.M.T.Somers@tue.nl

Jonas Galle

jonas.galle@ugent.be

Sabastion Verhelst

sebastian.verhelst@ugent.be

\section{ACKNOWLEDGMENTS}

The financial support of technology foundation STW, Paccar., Shell Global Solutions and Avantium is gratefully acknowledged, as well as the in-kind contributions from: Lyle Pickett (Sandia), Julien Manin (Sandia), Gilles Bruneaux (IFPEN), Louis-Marie Malbec (IFPEN) and Michele Bardi (CMT).

\section{DEFINITIONS/ABBREVIATIONS}

ID - Ignition Delay

FLOL - Flame Lift-Off Length

std - Standard deviation 
Meijer et al / SAE Int. J. Engines / Volume 6, Issue 2(June 2013)

DBI - Diffused Back Illumination

LL - Liquid Length

EHPC - Eindhoven High Pressure Cell

ASOI - After Start Of Ignition 